\title{
IMPLEMENTASI EKSTRAKURIKULER CABANG OLAHRAGA FUTSAL PUTRI PADA SEKOLAH MENENGAH ATAS DI KOTA BENGKULU
}

\author{
Bunga Surya Ningrum¹, Yarmani $^{2}$, Sofino $^{3}$ \\ ${ }^{123}$ Prodi Penjas, FKIP, Universitas Bengkulu, Kota Bengkulu, Indonesia
}

\begin{tabular}{l} 
Info Artikel \\
\hline Sejarah Artikel: \\
Diterima April 2020 \\
Direvisi April 2020 \\
Diterima April 2020 \\
Tersedia online April 2020 \\
- \\
Pata kunci: \\
Prasaran
\end{tabular}

\begin{abstract}
Abstrak
Penelitian ini bertujuan untuk mengetahui penerapan yang ada di Sekolah Menengah Atas Kota Bengkulu dengan 5 item yaitu : 1. Pengelolaan, 2. Minat dan keikutsertaan, 3. Sarana dan prasarana, 4. Pelaksanaan, 5. Pendanaan Ekstrakurikuler Futsal putri pada Sekolah Menengah Atas di Kota Bengkulu. Metode yang digunakan dalam penelitian ini adalah metode deskriptif kualitatif. Dengan obyek penelitian yang berjumlah 50 Siswi dengan 5 Sekolah Menengah Atas yang masing-masing, SMA Negeri 1 Kota Bengkulu sebanyak 11 Siswi, SMA Negeri 3 Kota Bengkulu sebanyak 10 Siswi, SMA Negeri 4 Kota Bengkulu sebanyak 12 Siswi, SMA Negeri 6 Kota Bengkulu sebanyak 8 Siswi dan SMA Muhammadiyah 4 Kota Bengkulu sebanyak 9 Siswi. Berdasarkan data yang diperoleh dari 5 sekolah yang memiliki ekstrakurikuler futsal putri dapat disimpulkan bahwa implementasi ekstrakurikuler cabang olahraga futsal putri pada Sekolah Menengah Atas di Kota Bengkulu dinyatakan dalam kategori baik dengan rata-rata hasil persentase $70,18 \%$.
\end{abstract}

\begin{abstract}
This study aims to determine the application in Bengkulu City High School with 5 items, namely: 1. Management, 2. Interests and participation, 3. Facilities and infrastructure, 4. Implementation, 5. Funding for female Futsal Extracurricular at Senior High Schools in Bengkulu City. The method used in this research is descriptive qualitative method. With research objects totaling 50 students with 5 high schools each, 11 SMA Negeri 1 Bengkulu City, 10 SMA Negeri 3 Bengkulu City, 12 SMA Negeri 4 Bengkulu City, 8 SMA Negeri 6 Bengkulu City and Muhammadiyah 4 High Schools Bengkulu City 9 Students. Based on data obtained from 5 schools that have female futsal extracurricular it can be concluded that the extracurricular implementation of female futsal sports in high
\end{abstract}




\begin{tabular}{lr}
\hline \multicolumn{2}{c}{$\begin{array}{c}\text { schools in Bengkulu City is stated in good category with an average } \\
\text { yield of } 70.18 \% .\end{array}$} \\
\hline $\begin{array}{l}\text { Alamat yang sesuai: Jl. Raden Fatah, Kota Bengkulu } \\
\text { Email } \quad: \text { bungasurya1711 @gmail.com }\end{array}$ & ISSN (online) \\
\end{tabular}

\section{PENDAHULUAN}

Kesadaran masyarakat Indonesia akan pentingnya pemeliharaan kesehatan sangat diperlihatkan selama manusia menghendaki untuk hidup sehat, baik sehat secara jasmani maupun kesehatan rohani. Hal ini terbukti dengan meningkatnya minat masyarakat dalam melakukan olahraga seperti olahraga permainan, atletik, olahraga air, beladiri dan lain - lain. Banyak cara yang dilakukan orang untuk menjaga kondisi tubuhnya agar tetap prima dan bugar. Salah satunya adalah dengan berolahraga, karena dengan olahraga sangat bermanfaat bagi kesehatan tubuh, selain itu rekreasi, dan olahraga juga bisa untuk mengembangkan prestasi.

\section{Berdasarkan Undang-Undang} Republik Indonesia nomor 3, (2005:2) tentang Sistem Keolahragaan Nasional "Olahraga adalah segala kegiatan yang sistematis untuk mendorong, membina, serta mengembangkan potensi jasmani, rohani, dan sosial". Olahraga merupakan perjuangan melawan diri sendiri dan melawan orang lain. Pada saat ini juga harus dilandasi sikap batiniah tertentu. Sikap batin yang dimaksud diaplikasikan dengan semangat kebenaran dan kejujuran serta tunduk kepada peraturanperaturan baik yang tersurat maupun yang tersirat. Sikap batin yang demikian itu berisi "Fair Play", dan ini perlu dikembangkan untuk melindungi bahayabahaya yang mengancamnya. Harsuki (2003 : 10) dalam Dony Andrijanto (2013 : 93)

Bermain futsal merupakan kegemaran hampir tiap lapisan masyarakat Indonesia. Baik di lapangan futsal atau dimana pun, orang-orang dapat bermain futsal tanpa mengurangi kesenangan yang ada di dalamnya. Futsal dimainkan oleh dua tim yang masingmasing tim terdiri dari lima pemain. Futsal tidak hanya digemari oleh lakilaki, namun wanita mulai tertarik bermain futsal. Perkembangan futsal wanita di Indonesia dapat dirasakan saat ini. Apalagi, kini si berbagai sekolah, banyak yang sudah membukan ekstrakurikuler futsal perempuan. Tidak hanya itu, klubklub futsal di universitas dan umum sudah mulai menjamur di Indonesia. Pertandingan futsal semakin marak diadakan, dan hal tersebut semakin membuat minat wanita untuk bermain futsal semakin tinggi.

Implementasi merupakan suatu tindakan atau pelaksanaan dari sebuah rencana yang sudah disusun secara matang dan terperinci. Dengan kata lain, implementasi bisa dikatakan sebagai bentuk penerapan ke lapangan secara 
langsung atas rencana yang telah dibuat dan disusun secara matang dan terperinci. Menurut Peraturan Menteri Pendidikan Nasional Republik Indonesia Nomor 39 Tahun 2008 tentang Pembinaan kesiswaan. Kegiatan ekstrakurikuler yang diikuti dan dilaksanakan oleh siswa baik di sekolah maupun diluar sekolah, bertujuan agar siswa dapat memperkaya dan memperluas diri. Setiap ekstrakurikuler mempunyai pengelolaan atau pengaturan yang berbeda dalam mengatur kebutuhan atlet dan timnya. Mulai dari jadwal, transportasi, pendanaan, dan berbagai kebutuhan hingga yang paling kecil dari tim. Sementara itu, belum diketahui seberapa tinggi pengelolaan pada tiap-tiap kegiatan ekstrakurikuler futsal putri pada Sekolah Menengah Atas di Kota Bengkulu. Sekolah yang memiliki ekstrakurikuler futsal putri diantaranya yaitu : SMA Negeri 1 Kota Bengkulu, SMA Negeri 3 Kota Bengkulu, SMA Negeri 4 Kota Bengkulu, SMA Negeri 6 Kota Bengkulu, dan SMA Muhammadiyah 4 Bengkulu.

Perkembangan futsal putri di Bengkulu saat ini sudah mulai berkembang pesat, terbukti dengan banyaknya club-club futsal putri yang telah terbentuk. Club futsal putri di bengkulu peminatnya mayoritas anak Sekolah Menengah Atas dan Mahasiswa aktif yang ada di Kota Bengkulu. Dengan semakin banyaknya club futsal putri yang ada di Kota Bengkulu membuat pihak Sekolah Menengah Atas dan pihak Universitas membentuk ekstrakurikuler futsal putri.
Peneliti melakukan observasi ke seluruh Sekolah Menengah Atas yang ada ekstrakurikuler futsal putri di Kota Bengkulu untuk melihat bagaimana penerapan kegiatan ekstrakurikuler olahraga, serta menjadi bagian pembinaan akademis di Sekolah Menengah Atas khususnya pada ekstrakurikuler cabang olahraga futsal. Faktor pendukung seperti Saranaprasarana, pengelolaan, program latihan, dan pendanaan, merupakan aspek-aspek yang diobservasi oleh peneliti. Berdasarkan observasi awal yang dilakukan peneliti pada tanggal 15 Januari sampai dengan tanggal 22 Januari 2019, diketahui bahwa ekstrakurikuler futsal putri di Sekolah Menengah Atas sejatinya sudah mulai berkembang, hanya saja masih banyaknya hambatan dalam proses penerapan ekstrakurikuler seperti ; kurangnya waktu latihan, kurangnya sarana dan prasarana yang ada, kurangnya pendanaan dalam pelaksanaan ekstrakurikuler, kurangnya minat dan keikutsertaan siswi dalam ekstrakurikuler futsal putri.

Dari uraian yang telah dipaparkan di atas, peneliti merasa sangat perlu untuk melakukan penelitian secara mendalam tentang kegiatan ekstrakurikuler futsal putri, dengan memberi judul penelitian, yaitu: "Implementasi Ekstrakurikuler Cabang Olahraga Futsal Putri Pada Sekolah Menengah Atas Di Kota Bengkulu". 


\section{METODE}

Berdasarkan permasalahan dan tujuan penelitian yang telah dibahas sebelumnya, maka metode yang digunakan dalam penelitian yang berjudul implementasi ekstrakurikuler cabang olahraga futsal putri pada Sekolah Menengah Atas di Kota Bengkulu yaitu metode deskriptif kualitatif. Metode penelitian ini muncul karena terjadi perubahan paradigma dalam memandang suatu realitas/ gejala/ fenomena. Penelitian deskriptif merupakan penelitian yang benar-benar hanya memaparkan apa yang terdapat atau terjadi dalam sebuah kancah, lapangan, atau wilayah tertentu. Data yang terkumpul disklasifikasikan atau kelompok-kelompok menurut jenis, sifat, atau kondisinya. Sesudah datanya lengkap, kemudian dibuat sebuah kesimpulan, Suharsimi Arikunto ( 2006 : 3 ) dalam Aydil Putra (2018 : 13). Sesuai dengan pembahasan di atas, metode ini bertujuan untuk mendapatkan berbagai informasi yang lebih rinci dan mendalam sehingga dapat ditindak lanjuti sesuai dengan keperluan peneliti.

Pada penelitian ini subjek penelitian adalah 50 orang siswi (angket) dan 5 orang pelatih (wawancara) dari 5 Sekolah Menengah Atas yang memiliki ekstrakurikuler futsal putri. Dalam penelitian ini, peneliti menyediakan satu angket dengan menggunakan angket skala likert. Menurut Sugiyono (2011: 93) skala likert adalah skala yang digunakan untuk mengukur sikap, pendapat, dan persepsi seseorang atau sekelompok orang tentang fenomena. Dengan skala likert, maka variabel yang diukur akan dijabarkan menjadi indikator variabel. Kemudian indikator tersebut dijadikan sebagai titik tolak untuk menyusun item-item instrument yang dapat berupa perntanyaan. Jawaban dalam skala likert terdapat lima alternatif yaitu (5) sangat setuju; (4) setuju; (3) ragu-ragu; (2) tidak setuju; (1) sangat tidak setuju.

Dalam skala likert perhitungan nilainya menggunakan rumus $\mathrm{P}=\mathrm{f} / \mathrm{n} \mathrm{x}$ $100 \%$ yang mana $P$ adalah persentase, $f$ adalah frekuensi jawaban seluruh responden, $\mathrm{n}$ adalah nilai ideal dan $100 \%$ adalah merupakan bilangan tetap. Sementara itu untuk mencari nilai ideal (n) menggunakan rumus $\mathrm{n}=$ nilai skala jawaban x jumlah responden (Sugiyono, 2011: 95). Menurut Sugiyono ( 2016:88 ) analisis data adalah proses mencari data menyusun secara sistematis data yang diperoleh dari hasil wawancara, catatan lapangan, dan dokumentasi, dengan cara mengorganisasikan data ke dalam kategori, menjabarkan ke dalam unit unit, melakukan sintesa, menyusun ke dalam pola, memilih mana yang penting dan yang dipelajari, dan membuat kesimpulan sehingga mudah dipahami oleh diri sendiri maupun orang lain.

Tabel 1. Pedoman Klasifikasi Skor

\begin{tabular}{c|c}
\hline KATEGORI & SKOR \\
\hline $81-100 \%$ & Sangat Baik \\
\hline $61-80 \%$ & Baik \\
\hline $41-60 \%$ & Sedang \\
\hline $21-40 \%$ & Kurang Baik \\
\hline$<20 \%$ & Sangat Kurang Baik \\
\hline
\end{tabular}

HASIL

a. SMA Negeri 1 Kota Bengkulu

Tabel 2. Persentase Implementasi

Ekstrakurikuler Futsal Putri di SMA Negeri 1 Kota Bengkulu

\begin{tabular}{l|l|c}
\hline No & Indikator dalam & Persentase \\
\hline 1 & $\begin{array}{l}\text { Organisasi } \\
\text { Pengeolaan }\end{array}$ & \\
\hline 2 & Minat dan Keikutsertaan & $80 \%$ \\
\hline
\end{tabular}




\begin{tabular}{l|l|l}
\hline 3 & Sarana dan Prasarana & $78,18 \%$ \\
\hline 4 & Pelaksanaan & $63,64 \%$ \\
\hline 5 & Pendanaan & $63,64 \%$ \\
\hline
\end{tabular}

b. SMA Negeri 3 Kota Bengkulu

Tabel 3. Persentase Implementasi Ekstrakurikuler Futsal Putri di SMA Negeri 3 Kota Bengkulu

\begin{tabular}{l|lr|c}
\hline No & Indikator & Persentase \\
\hline 1 & $\begin{array}{l}\text { Organisasi dalam } \\
\text { Pengeolaan }\end{array}$ & $74 \%$ \\
\hline 2 & $\begin{array}{l}\text { Minat dan } \\
\text { Keikutsertaan }\end{array}$ & $80 \%$ \\
\hline 3 & $\begin{array}{l}\text { Sarana dan } \\
\text { Prasarana }\end{array}$ & $62 \%$ \\
\hline 4 & Pelaksanaan & $64 \%$ \\
\hline 5 & Pendanaan & $58 \%$ \\
\hline
\end{tabular}

c. SMA Negeri 4 Kota Bengkulu

Tabel 4. Persentase Implementasi Ekstrakurikuler Futsal Putri di SMA Negeri 4 Kota Bengkulu

\begin{tabular}{l|l|c}
\hline No & Indikator & Persentase \\
\hline 1 & $\begin{array}{l}\text { Organisasi dalam } \\
\text { Pengeolaan }\end{array}$ & $60 \%$ \\
\hline 2 & $\begin{array}{l}\text { Minat dan } \\
\text { Keikutsertaan }\end{array}$ & $65 \%$ \\
\hline 3 & $\begin{array}{l}\text { Sarana dan } \\
\text { Prasarana }\end{array}$ & $61,67 \%$ \\
\hline 4 & Pelaksanaan & $58,33 \%$ \\
\hline 5 & Pendanaan & $58,33 \%$ \\
\hline
\end{tabular}

d. SMA Negeri 6 Kota Bengkulu

Tabel 5. Persentase Implementasi Ekstrakurikuler Futsal Putri di SMA Negeri 6 Kota Bengkulu

\begin{tabular}{l|l|c}
\hline No & Indikator & Persentase \\
\hline 1 & $\begin{array}{l}\text { Organisasi } \\
\text { dalam }\end{array}$ & $60 \%$ \\
\hline 2 & $\begin{array}{l}\text { Pengeolaan } \\
\text { Kinat dan }\end{array}$ & $72,5 \%$ \\
\hline
\end{tabular}

\begin{tabular}{l|l|c}
\hline 3 & $\begin{array}{l}\text { Sarana dan } \\
\text { Prasarana }\end{array}$ & $77,5 \%$ \\
\hline 4 & Pelaksanaan & $60 \%$ \\
\hline 5 & Pendanaan & $60 \%$ \\
\hline
\end{tabular}

e. SMA Muhammadiyah 4 Kota Bengkulu

Tabel 6. Persentase Implementasi Ekstrakurikuler Futsal Putri di SMA Muhammadiyah 4 Kota Bengkulu

\begin{tabular}{l|lr|c}
\hline No & Indikator & Persentase \\
\hline 1 & $\begin{array}{l}\text { Organisasi dalam } \\
\text { Pengeolaan }\end{array}$ & $71 \%$ \\
\hline 2 & $\begin{array}{l}\text { Minat dan } \\
\text { Keikutsertaan }\end{array}$ & $75,5 \%$ \\
\hline 3 & $\begin{array}{l}\text { Sarana dan } \\
\text { Prasarana }\end{array}$ & $71,43 \%$ \\
\hline 4 & Pelaksanaan & $64,75 \%$ \\
\hline 5 & Pendanaan & $59,55 \%$ \\
\hline
\end{tabular}

Dari hasil rata-rata keseluruhan atas 5 sekolah yang memiliki ekstrakurikuler futsal putri di Kota Bengkulu bahwa persentase implementasi ekstrakurikuler futsal putri pada Sekolah Menengah Atas di Kota Bengkulu yaitu $70,18 \%$ dan dapat di kategorikan baik.

Berdasarkan hasil persentase yang telah diperoleh bahwa implementasi ekstrakurikler futsal putri di SMA Negeri 1 Kota Bengkulu di kategorikan baik dengan hasil persentase $76 \%$, SMA Negeri 3 Kota Bengkulu di kategorikan baik dengan hasil persentase $65,92 \%$, SMA Negeri 4 Kota Bengkulu di kategorikan baik dengan hasil persentase 60, 67\%, SMA Negeri 6 Kota Bengkulu di kategorikan baik dengan hasil persentase $76,8 \%$, dan SMA Muhammadiyah 4 di kategorikan baik dengan hasil persentase $74,58 \%$. 


\section{PEMBAHASAN}

Pembahasan dari penelitian yang telah dilakukan adalah sebagai berikut :

\section{Organisasi dalam Pengelolaan}

Mengemukakan

pengorganisasian yaitu pengaturan pekerjaan dan pengalokasian pekerjaan di antara anggota organisasi sehingga tujuan organisasi dapat dicapai secara efisien (Sabardi, 2014). Berdasarkan data yang diambil dari 5 sekolah yang diteliti bahwa dapat dilihat organisasi dalam pengelolaan ekstrakurikuler futsal putri di kategorikan baik. Di SMA Negeri 1 sudah terlihat dengan banyaknya prestasi yang diraih dan walaupun prestasi yang diraih SMA Muhammadiyah 4 belum maksimal tetapi struktur organisasi dan pengelolaan ekstrakurikuler futsal terstruktur, sedangkan SMA Negeri 3 belum ada prestasi yang diraih dan organisasi masih belum terstruktur.

\section{Minat dan Keikutsertaan}

Minat adalah suatu fungsi jiwa untuk dapat mencapai sesuatu yang merupakan kekuatan di dalam dan tampak di luar sebagai gerak - gerik. Dalam menjalankan fungsinya minat berhubungan erat dengan pikiran dan perasaan. Manusia memberi corak dan menentukan sesudah memilih dan mengambil keputusan. Perubahan minat memilih dan mengambil keputusan disebut keputusan kata hati (Heri, P, 1998) dalam Sarjanaku.com (2016).

Berdasarkan hasil penelitian menyatakan bahwa dari 5 sekolah yang memiliki ekstrakurikuler futsal putri 3 di antaranya SMA Negeri 1 Kota Bengkulu, SMA Negeri 6 Kota Bengkulu dan Muhammadiyah 4 Kota Bengkulu minat dan keikutsertaan siswi dalam ekstrakurikuler futsal dapat di kategorikan baik dalam menunjang prestasi berdasarkan keaktifan siswi dalam mengikuti kegiatan latihan, maupun turnamen. Sedangkan 2 sekolah di antaranya SMA Negeri 3 Kota Bengkulu dan SMA Negeri 4 Kota Bengkulu minat dan keikutsertaan siswi baik tetapi keaktifan siswi dalam mengikuti kegiatas latihan masih kurang dalam menunjang prestasinya.

\section{Sarana dan Prasarana}

$\begin{array}{rrr}\text { Menurut Kamus Besar Bahasa } \\ \text { Indonesia } & (\mathrm{KBBI}) & \text { dalam }\end{array}$

Sumberpengertian.id (2018) Sarana adalah segala sesuatu yang dapat dipakai sebagai alat dalam mencapai maksud atau tujuan. Prasarana adalah segala sesuatu yang merupakan penunjang utama terselenggaranya suatu proses (usaha, pembangunan, proyek).

Dari hasil penelitian diperoleh dari keseluruhan sarana dan prasarana kegiatan ekstrakurikuler futsal putri pada Sekolah Menegah Atas di Kota Bengkulu termasuk kategori baik, yaitu sarana dan prasarana olahraga futsal yang digunakan untuk latihan cukup memadai dalam pelaksanaan ekstrakurikuler futsal. Sebagian untuk kegiatan sudah terpenuhi seperti cones / corong, bola yang digunakan cukup untuk latihan, lapangan yang cukup baik, ada rompi dan gawang, hanya saja di SMA Negeri 4 Kota Bengkulu dan SMA Negeri 3 Kota Bengkulu kurangnya perhatian dari pihak sekolah sehingga masih banyak sarana dan prasarana yang kurang memadai.

Proses ekstrakurikuler futsal akan berjalan dengan lancar jika ditunjang dengan sarana dan prasarana yang memadai, dengan kelengkapan alat penunjang untuk ekstrakurikuler futsal.

\section{Pelaksanaan}

Kegiatan ekstrakurikuler adalah kegiatan pendidikan diluar mata pelajaran 
dan di luar pelayanan konseling untuk membantu pengembangan siswi sesuai dengan kebutuhan, potensi, bakat dan minat mereka melalui kegiatan yang secara khusus diselenggarakan oleh pendidik atau tenaga pendidikan yang berkemampuan dan berkewenangan di sekolah (Noor, 2015).

Pelaksanaan ekstrakurikuler futsal putri di SMA Muhammadiyah 4 di kategorikan baik dapat dilihat dari semangat siswi dalam melaksanakan program latihan yang diberikan oleh pelatih berjalan dengan baik dan selalu mengikuti kegiatan turnamen yang ada di Kota Bengkulu. Namun di SMA Negeri 4 Kota Bengkulu masih di kategorikan sedang karena kurangnya peran siswi dalam mengikuti kegiatan latihan dan program latihan yang diberikan pelatih belum berjalan seperti yang di harapkan.

Hasil penelitian ini didukung dengan hasil wawancara dan kuesioner dengan beberapa guru atau pengajar yang telah membina dan mengajarkan ekstrakurikuler futsal putri di Sekolah Menengah Atas Kota Bengkulu.

\section{Pendanaan}

Berdasarkan hasil penelitian pendanaan dalam ekstrakurikuler futsal putri dapat di kategorikan kurang baik, karena kurangnya dukungan dari pihak sekolah. Keterbatasan sekolah dalam mengadakan dan menyediakan dana menyebabkan kurangnya sarana dan prasarana, dengan keterbatasan dana masih banyak sekolah yang menggunakan dana pribadi ketika ingin mengikuti turnamen.

Berdasarkan prosedur penelitian yang dirancang dan dilaksanakan dengan sistematis dan terencana dengan baik, maka peneliti dapat mengumpulkan datadata penelitian yang merupakan informasi penting hasil penelitian seperti yang disajikan dalam deskripsi penelitian diatas. Penelitian ini menggunakan metode deskriptif kualitatif. Pendanaan ekstrakurikuler futsal putri di Sekolah Menegah Atas di Kota Bengkulu dapat di kategorikan sedang di lihat dari 5 sekolah yang di teliti bahwa kurang dukungan dari pihak sekolah seperti dana untuk mengikuti kegiatan turnamen seperti di SMA Negeri Muhammadiyah 4 siswi menggunakan iuran uang kas untuk kegiatan turnamen.

\section{SIMPULAN}

Berdasarkan perolehan data implementasi ekstrakurikuler futsal putrid pada Sekolah Menengah Atas di Kota Bengkulu harus memperhatikan indikator organisasi dalam pengolaan ekstrakurikuler, minat dan keikutsertaan siswi dalam ekstrakurikuler futsal, sarana dan prasarana, pelaksanaan ekstrakurikuler, dan pendanaan. Tanpa organisasi yang baik dalam pengelolaan ekstrakurikuler futsal putri akan menghambat proses pendanaan dan sarana prasarana dari pihak sekolah, program latihan dalam pelaksanaan kegiatan ekstrakurikuler sangat penting demi menunjang prestasi siswi. Berdasarkan data yang diperoleh dari 5 sekolah yang memiliki ekstrakurikuler futsal putri dapat disimpulkan bahwa implementasi ekstrakurikuler cabang olahraga futsal putrid pada Sekolah Menengah Atas di Kota Bengkulu dinyatakan dalam kategori baik dengan rata-rata hasil persentase $70,18 \%$.

\section{Saran-saran}

1. Diharapkan adanya perhatian khusus yang diberikan pihak Sekolah kepada pelatih maupun siswi yang mengikuti Ekstrakurikuler Futsal Putri agar mereka lebih bersemangat dan 
memotivasi mereka untuk mengikuti Ekstrakurikuler tersebut.

2. Diharapkan pihak Sekolah untuk ikut adil dalam anggaran yang dikeluarkan untuk Ekstrakurikuler Futsal Putri.

3. Pada proses latihan yang sedang berlangsung hendaknya pelatih maupun siswi agar lebih tepat waktu supaya proses latihan berjalan dengan seefektif mungkin.

4. Diharapkan untuk pelatih dapat membuat program latihan yang menarik dan tidak membosankan.

5. Kepada siswi yang berlatih agar lebih giat lagi dan bersemangat untuk menargetkan prestasi di turnamen/pertandingan yang lebih tinggi.

\section{DAFTAR PUSTAKA}

Dony Andrijanto. 2013. Minat Siswa Dalam Mengikuti Ekstrakurikuler Futsal Studi Pada Siswa Peserta Ekstrakurikuler Futsal Di Smp Negeri 2 Buduran. Universitas Negeri Surabaya.

Ginting, S. S. (2019). Analisis Kemampuan Teknik Control, Heading dan Passing Siswa Ekstrakurikuler Futsal SMP Negeri 13 Kota Bengkulu. Kinestetik: Jurnal Ilmiah Pendidikan Jasmani, 3(1), 118-124.

Noor, J. 2015. Pelaksanaan Layanan Bimbingan Kelompok Dalam Pembinaan Kegiatan Ekstrakurikuler di SMP Negeri 1 Rantau Tahun 2014. Universitas Islam Kalimantan Muhammad Arsyad Al Banjary Banjarmasin.

Putra, A., Yarmani, Y., \& Arwin, A. IMPLEMENTASI PUSAT PENDIDIKAN DAN LATIHAN OLAHRAGA PELAJAR (PPLP) DALAM MENUNJANG PRESTASI OLAHRAGA $B E N G K U L U$ (Doctoral dissertation, Universitas Bengkulu).
Peraturan Menteri Pendidikan Nasional Republik Indonesia Nomor 39 Tahun 2008 tentang Pembinaan kesiswaan.

Rahmadianti, T., \& Sugihartono, T. (2019). ANALISIS PERKEMBANGAN EKSTRAKURIKULER FUTSAL DITINGKAT SMP NEGERI KOTA BENGKULU. Kinestetik: Jurnal Ilmiah Pendidikan Jasmani, 3(2), 223-229.

Saputra, R. N., \& Yarmani, Y. (2019) PENGARUH METODE LATIHAN TERPUSAT DAN METODE LATIHAN ACAK TERHADAP KEMAMPUAN TEKNIK DASAR FUTSAL. Kinestetik: Jurnal Ilmiah Pendidikan Jasmani, 3(1), 108-117.

Sarjanaku.com. 2016. [Review] Pengertian Minat Menurut Para Ahli Artikel Definisi Minat. http://www.sarjanaku.com/2012/12/pe ngertian-minat-menurut-para-ahli.html

Sugiyono. ( 2011 ). Metode Penelitian Kuantitatif Kualitatif R \& D. Bandung: alfabel.

Undang - Undang Republik Indonesia Nomor 3 Tahun 2005 Tentang Sistem Keolahragaan Nasional 